This is the peer reviewed version of the following article:

Lam, T. and Lenton, S. and Burns, L. and Aiken, A. and Ogeil, R. and Gilmore, W. and Chikritzhs, T. et al. 2015. Alcohol policy impact on young risky drinkers and their support for proposed measures. Australian and New Zealand Journal of Public Health. 39 (2): pp. 129134.,

which has been published in final form at http://doi.org/10.1111/1753-6405.12326

This article may be used for non-commercial purposes in accordance with Wiley Terms and Conditions for Self-Archiving at http://olabout.wiley.com/WileyCDA/Section/id-

820227.html\#terms 


\section{Alcohol policy impact on young risky drinkers and their support for proposed measures}

Tina Lam ${ }^{1}$ Simon Lenton ${ }^{1}$ Lucinda Burns $^{2}$ Alexandra Aiken² Rowan Ogeil ${ }^{3,4}$ William Gilmore ${ }^{1}$ Tanya Chikritzhs ${ }^{1}$ Belinda Lloyd ${ }^{3,4}$ Dan Lubmann ${ }^{3,4}$ Richard Mattick ${ }^{2}$ Steve Allsop ${ }^{1}$

${ }^{1}$ National Drug Research Institute, Curtin University, Faculty of Health Sciences, Western Australia

2 National Drug and Alcohol Research Centre, University of New South Wales

${ }^{3}$ Eastern Health Clinical School, Monash University, Victoria

${ }^{4}$ Turning Point, Eastern Health, Victoria

Correspondence to: Dr Tina Lam, National Drug Research Institute, Curtin University. GPO Box U1987, Perth, WA 6845; e-mail: Tina.lam@curtin.edu.au

The authors have stated they have no conflict of interest.

Keywords

Alcohol; Alcohol consumption; Young people; Adolescents; Young adults; Alcohol availability; Alcohol policy; Alcohol sources; Alcohol use; Underage youth; risky single occasion drinking; Risky drinking 


\section{Alcohol policy impact on young risky drinkers and their support for proposed measures}

\section{Abstract}

Objective

To explore impacts of existing policies on young Australian risky drinkers' access to alcohol and to gauge their support for proposed alcohol measures.

Methods

The 16-19 year old participants were recruited from three Australian states using non-random convenience sampling, for either a face-to-face or online quantitative survey $(\mathrm{N}=958)$. The sample was deliberately selected to represent drinkers whose consumption placed them in the riskiest drinking 20$25 \%$ of their age bracket.

Results

Half (49\%) of the sample who were younger than the Australian legal purchase age reported it was 'easy' to purchase alcohol from bottle stores, and $75 \%$ of those who had tried to purchase alcohol, said it was 'easy' the last time they tried. Half of those under 18, who had attempted to enter a licensed venue, reported they did not have their identification checked last time they gained access. Ninety percent of all respondents drank within a private location at their last risky drinking session. Sixty-five percent supported 'increasing the price of [alcohol by $20 \notin]$ a standard drink if the extra $20 \notin$ was used to support prevention and treatment of alcohol problems'.

\section{Conclusions}

Age- or intoxication-based restrictions to alcohol were commonly bypassed.

\section{Implications}

Point of sale alcohol controls require improvement to prevent under age access. Given that a significant proportion of drinking occasions for those under 18 occurred in private premises, prevention strategies need to target these locations. There were diverse levels of support for strategies to reduce harm, including potential community backing for an evidence-based proposed price policy. 


\section{Introduction}

There is ongoing public and political concern about harms associated with risky alcohol consumption, especially among young people. In Australia, there appears to be two diverging trends. Firstly, there is evidence that more young people choose to abstain from alcohol - in 2005, $14 \%$ of Australian school children (aged 12-17) had never used alcohol, whereas in 2011 this rate was significantly higher at 26\% (1, 2). However, those who are drinking, appear to be doing so at riskier levels - and there has been an associated increase in alcohol-related hospital and emergency admissions among young Australians (3).

This paper presents data from a sample of the heaviest drinking $20-25 \%$ of $16-19$ year olds in three Australian cities and one regional centre. These risky drinkers tend to be underrepresented in national alcohol and other drug surveys $(2,4)$, but are overrepresented in harm statistics.

In 2010, the overall national cost of alcohol related harms was estimated to be 14 billion dollars, more than double the tax revenue generated through the sale of alcohol (5). Previous research suggests that young people may be overrepresented in both harms and their related costs; for example, 15-24 year olds account for $32 \%$ of all alcohol-attributable hospital admissions for violent injuries, and $52 \%$ of all alcohol-related serious road injuries $(6,7)$ demanding a comprehensive range of responses (8).

Identified strategies have included controls on the exposure of young people to alcohol promotions, including at sporting events, reshaping supply toward lower risk products, addressing the cultural place of alcohol, and supporting brief interventions within a primary healthcare settings (8-10).

A key strategy is control on the availability of alcohol. Alcohol might be controlled through limitations on who can purchase alcohol, hours and days of sale, which outlets can supply alcohol, and the nature of outlets, and price. In Australia, the majority of alcohol is purchased through 'off-site' premises such as retail bottle stores, for consumption in locations such as private homes (11). Alcohol can also be consumed 'on-site' from where it was purchased in premises such as pubs, clubs, or restaurants. In both 
cases, state liquor legislation requires licensees and their staff to not sell alcohol to anyone under the age of 18 , or to serve an intoxicated individual (12).

This study's sample of 16-19 year olds were in 'transition' period, soon to move, or having moved recently to a 'legal purchase' age. This paper outlines their perceptions and past experiences with these age and intoxication-based enforcement practices as well as other influences on their access to alcohol, such as outlet distance, with increased outlet density associated with an increased risk of alcohol consumption $(13,14)$. In addition to exploring these impacts, this paper also aimed to gauge their support for proposed alcohol policy measures.

There is sometimes a gap between evidence and what is acceptable to governments and communities. For example, whilst there is consistent evidence about the impact of price (15-17), price measures can be contentious $(15,18)$. Less than half $(43 \%)$ of all Australians support 'increasing tax on alcohol to pay for health, education and treatment of alcohol-related problems' (19). Young people, especially those who consume higher quantities typically report the lowest levels of support for such policies. For example, in 2010, the same measure was supported by only $16 \%$ of Australians aged 14 and older who drank more than 4 standard drinks at least weekly. To inform the development of effective and acceptable prevention, it is important to not just gauge the impact of policy on behaviour, but also to assess perceptions of policy levers and to identify what might influence their acceptability/rejection (15). Thus, while price levers tend to be unpopular, there is some evidence that they might be more acceptable if any price increase is directed to prevention or treatment effort, as occurred in the Northern Territory two decades ago $(20,21)$.

The current study was conducted as a feasibility study to demonstrate the utility of recruitment of sentinel high risk groups of heavy/risky young drinkers in each Australian jurisdiction in order to monitor trends in consumption, harm and attitudes among this important group. Based broadly on the Illicit Drug Reporting System (IDRS; 22) and the Ecstasy and related Drugs Reporting System (EDRS; 23), the project aims to accumulate data about risk and harm and monitor trend, which can change rapidly among 
young risky drinkers who may be under-represented in the National Drug Strategy Household Survey (4) or the Australian secondary school students' Survey (2) which are conducted every three years.

\section{Methods}

\section{Procedure}

This study, combined face-to-face and Internet surveys within a non-probability-based sampling framework. Recruitment occurred primarily through social media advertising (70\%), but also through snowballing (15\%), and posters placed at universities/technical colleges and youth specific services (4\%). The participants were aged 16-19 years and were recruited for either an interviewer-administered interview or for a self-administered online survey.

Participants were screened for age and consumption inclusion criteria via telephone, email, or the online survey's skip logic programming prior to survey administration. The face-to-face interviews (F2F) interviews ran for approximately 30 minutes and were conducted in the cities of Sydney (29\%), Melbourne (27\%), Perth (25\%), and the regional Western Australian town of Bunbury (19\%; $\mathrm{N}=351)$. The F2F interviews had quotas to ensure gender and age balance, and so that no more than half of the 18-19 year old age group were university students (to make sure we did not have overrepresentation of university students). Once 100 interviews per site were completed, eligible young people were referred to the online survey. Respondents could also access the online survey through the project website. The online instrument was an abbreviated version of the F2F interview with a completion time of 15 minutes $(\mathrm{N}=607)$. These online surveys were open to all Australian residents aged 16-19 who fulfilled the selection criteria (described below), but were concentrated in regions where paid advertising occurred ( $41 \%$ Perth, $33 \%$ Melbourne, 7\% Sydney, 13\% regional WA). The F2F interviewees were reimbursed $\$ 40$ in cash for their time. The online participants were placed in a prize draw for one of $50 \$ 20$ retail vouchers. Data were collected in 2013 as a part of a larger study about the context of risky alcohol consumption (alcohol quantities, beverage types, other drug use, harms, protective strategies etc.). Ethics approval was granted by Curtin University, St John of God Health Care, Monash University, and the University of New South Wales. 


\section{Sample}

Inclusion criteria that best captured this population were developed based on data sources relevant to this population; the 2009 Victorian Youth Alcohol and Drugs Survey (VYADS)(24), and the 2010 National Drug Strategy Household Survey (NDSHS)(4). Based on these data sources, this study defined regular drinking as consumption at least twice a month, and risky levels as 7 or more standard drinks. A higher level of 11 or more standard drinks was set for 18-19 year old males due to the higher rates of consumption among this group. The age and gender questions were presented prior to items about consumption to determine whether the $7+$ or $11+$ criterion was applicable to the respondent. As risky alcohol consumption was a part of the inclusion criteria, the behaviour reported here are by definition less conservative than those of 16-19 year olds identified in broad population samples. Of the 958 participants, 499 were female (52\%), 457 were male (48\%), 2 of other gender, 191 aged $16(20 \%), 329$ were 17 (34\%), 205 aged 18 (21\%) and 232 were aged 19 (24\%). Most were in full time study (36\% in school, $32 \%$ in university, $8 \%$ in TAFE), $9 \%$ were unemployed, $6 \%$ full time employed, $3 \%$ were trade apprentices, 3\% otherwise occupied, and most and lived with their parents (80\%).

Although the study was established to demonstrate the utility of monitoring sentinel groups of high risk young drinkers, and as such the sample was not recruited to be representative of all such risky young drinkers, it was nevertheless of interest to explore how it compared to relevant representative samples. 'Risky' drinking subsamples of 16-19 year olds were selected from the NDSHS ( $\mathrm{n}=182)$ and VYADS $(n=597)$ to match the inclusion criteria used for YAARS. These samples were compared across alcohol consumption, location and disposable income. Compared to YAARS participants, VYADS respondents were 1.3 times as likely to report use of $20+$ standard drinks at least twice a month (logistic regression controlling for age, metro/non-metropolitan location and gender; $\mathrm{p}=0.04 ; 95 \% \mathrm{CI}$ with 1000 bootstrap samples [1.01-1.71]). There were no significant differences in the use of $20+$ standard drinks between the YAARS and NDSHS; or in the used of $11+$ standard drinks at least twice a month between the VYADS, YAARS and NDSHS samples. Respondents from the VYADS were 2.41 times as likely and the NDSHS were 2.91 as likely to have been drawn from a non-metropolitan area (80\% YAARS, 58\% NDSHS 63\% VYADS). The 16-17 year olds from the VYADS and YAARS reported similar disposable incomes. 
However, the 18-19 year olds drawn from the VYADS reported significantly higher recreational incomes ( $65 \%$ vs $75 \%$ reporting a weekly income of more than $\$ 80$ for recreational purposes).

\section{Analysis}

SPSS 21 was used to conduct all analyses and a $\mathrm{p}$ value of $<.05$ was used as a threshold for significance. Chi square tests for independence were used to compare groups' responses to ease of access (across the three response categories of easy, difficult and don't know/never tried). Mann-Whitney U tests were used to examine for gender and age differences in ordinal variables such as level of support. Analyses were restricted to cases with complete data on the variables involved in the analysis.

\section{Results}

\section{Ease of access}

Respondents were asked to rate how easy it was to access alcohol through a bottle store, to enter a licensed venue as someone under the age of 18 , and to enter a venue while intoxicated. The items asked how easy these tasks were for people in general, and in terms of their own experience (see table 1).

Half of the participants aged under 18 said it was 'easy' or 'very easy' in general, for under 18 s to purchase alcohol from the bottle store (51\%). Of the under 18s $(\mathrm{N}=301 ; 65 \%)$ who had previously attempted this, $75 \%$ said it was easy the last time they tried (49\% of total underage sample when including the 161 that had never tried). Unsurprisingly, the 18-19 year olds reported significantly different personal purchase experiences from their younger counterparts $\left(X^{2}[2, \mathrm{n}=867]=9.98, \mathrm{p}=.007\right)$. It appeared a smaller proportion of 18-19 year olds endorsed that it was easy to purchase while underage, and a larger proportion had never tried or did not know how easy such a purchase was.

Forty percent of those under the age of 18 said it was easy, in general, to get into a licensed venue as someone under the age of 18 , and $72 \%$ of those who had tried before said it was easy the last time they attempted access ( $41 \%$ of the entire underage sample). 
A fifth of those under 18 found it easy, in general, to enter a licensed venue while intoxicated (23\%), and of those who had tried to do so before, $59 \%$ found it easy the last time they tried (22\% of entire underage 18 sample). In comparison, the majority of the $18-19$ year olds found it easy, in general (52\%), and in their own experience $(71 \%)$, to enter a venue while intoxicated. There were significant age differences in these responses about general perception $\left(X^{2}[2, n=865]=118.53, p=0.001\right)$, and personal experience $\left(X^{2}\right.$ $[2, \mathrm{n}=866]=256.62, \mathrm{p}=0.001)$. 
Table 1. Ease of access to licensed venues

\begin{tabular}{|c|c|c|c|c|c|c|c|c|}
\hline & \multirow[b]{2}{*}{$\begin{array}{l}\text { Survey } \\
\text { modality }\end{array}$} & \multicolumn{3}{|c|}{ 16-17 year olds } & \multicolumn{3}{|c|}{ 18-19 year olds } & \multirow[t]{2}{*}{$\mathrm{p}$} \\
\hline & & $\mathrm{F} 2 \mathrm{~F}$ & Online & All & $\mathrm{F} 2 \mathrm{~F}$ & Online & All & \\
\hline \multirow{5}{*}{$\begin{array}{l}\text { How easy is it, in general, for } \\
\text { people under the age of } 18 \text { to } \\
\text { buy alcohol from the bottle } \\
\text { store? }\end{array}$} & Easy & $59.8 \%$ & $46.5 \%$ & $51.2 \%$ & $53.5 \%$ & $45.9 \%$ & $49.4 \%$ & \\
\hline & Difficult & $37.2 \%$ & $35.0 \%$ & $35.8 \%$ & $39.0 \%$ & $35.5 \%$ & $37.1 \%$ & \\
\hline & Don't know & $1.8 \%$ & $5.4 \%$ & $4.1 \%$ & $7.5 \%$ & $4.5 \%$ & $5.9 \%$ & \\
\hline & Never tried & $1.2 \%$ & $13.1 \%$ & $8.9 \%$ & $0.0 \%$ & $14.1 \%$ & $7.6 \%$ & \\
\hline & Total & 164 & 297 & 461 & 187 & 220 & 407 & \\
\hline \multirow{5}{*}{$\begin{array}{l}\text { The last time you tried, how } \\
\text { easy was it for YOU as } \\
\text { someone under the age of } 18 \text {, } \\
\text { to buy alcohol from the bottle } \\
\text { store? }\end{array}$} & Easy & $57.3 \%$ & $44.3 \%$ & $48.9 \%$ & $41.9 \%$ & $35.2 \%$ & $38.3 \%$ & \multirow{5}{*}{ ** } \\
\hline & Difficult & $11.0 \%$ & $14.8 \%$ & $13.4 \%$ & $14.0 \%$ & $19.2 \%$ & $16.8 \%$ & \\
\hline & Don't know & $1.2 \%$ & $3.7 \%$ & $2.8 \%$ & $1.1 \%$ & $2.3 \%$ & $1.7 \%$ & \\
\hline & Never tried & $30.5 \%$ & $37.2 \%$ & $34.8 \%$ & $43.0 \%$ & $43.4 \%$ & $43.2 \%$ & \\
\hline & Total & 164 & 298 & 462 & 186 & 219 & 405 & \\
\hline \multirow{5}{*}{$\begin{array}{l}\text { How easy is it, in general, for } \\
\text { people under the age of } 18 \text { to } \\
\text { get into a licensed venue? }\end{array}$} & Easy & $43.9 \%$ & $38.5 \%$ & $40.4 \%$ & $42.8 \%$ & $41.1 \%$ & $41.9 \%$ & \\
\hline & Difficult & $51.8 \%$ & $43.6 \%$ & $46.5 \%$ & $52.9 \%$ & $45.7 \%$ & $49.0 \%$ & \\
\hline & Don't know & $2.4 \%$ & $6.4 \%$ & $5.0 \%$ & $4.3 \%$ & $5.5 \%$ & $4.9 \%$ & \\
\hline & Never tried & $1.8 \%$ & $11.5 \%$ & $8.0 \%$ & $0.0 \%$ & $7.8 \%$ & $4.2 \%$ & \\
\hline & Total & 164 & 296 & 460 & 187 & 219 & 406 & \\
\hline \multirow{5}{*}{$\begin{array}{l}\text { The last time you tried, how } \\
\text { easy was it for YOU (as } \\
\text { someone under the age of } \\
\text { 18), to get into a licensed } \\
\text { venue? }^{1}\end{array}$} & Easy & $47.6 \%$ & $37.5 \%$ & $41.1 \%$ & $32.6 \%$ & & & \\
\hline & Difficult & $15.2 \%$ & $14.2 \%$ & $14.6 \%$ & $16.6 \%$ & & & \\
\hline & Don't know & $0.0 \%$ & $1.7 \%$ & $1.1 \%$ & $.5 \%$ & & & \\
\hline & Never tried & $37.2 \%$ & $46.6 \%$ & $43.3 \%$ & $50.3 \%$ & & & \\
\hline & Total & 164 & 296 & 460 & 187 & 219 & 406 & \\
\hline \multirow{5}{*}{$\begin{array}{l}\text { How easy is it, in general, for } \\
\text { people who are intoxicated to } \\
\text { get into a licensed venue? }\end{array}$} & Easy & $19.5 \%$ & $25.4 \%$ & $23.3 \%$ & $46.8 \%$ & $56.4 \%$ & $52.0 \%$ & \multirow{5}{*}{ ** } \\
\hline & Difficult & $65.9 \%$ & $37.3 \%$ & $47.5 \%$ & $48.9 \%$ & $37.7 \%$ & $42.9 \%$ & \\
\hline & Don't know & $13.4 \%$ & $15.3 \%$ & $14.6 \%$ & $4.3 \%$ & $4.1 \%$ & $4.2 \%$ & \\
\hline & Never tried & $1.2 \%$ & $22.0 \%$ & $14.6 \%$ & $0.0 \%$ & $1.8 \%$ & $1.0 \%$ & \\
\hline & Total & 164 & 295 & 459 & 186 & 220 & 406 & \\
\hline \multirow{5}{*}{$\begin{array}{l}\text { The last time you tried, how } \\
\text { easy was it for YOU to get } \\
\text { into a licensed venue while } \\
\text { intoxicated? }\end{array}$} & Easy & $24.5 \%$ & $19.9 \%$ & $21.6 \%$ & $71.1 \%$ & $70.9 \%$ & $71.0 \%$ & \multirow{4}{*}{ ** } \\
\hline & Difficult & $13.5 \%$ & $11.5 \%$ & $12.2 \%$ & $13.4 \%$ & $14.5 \%$ & $14.0 \%$ & \\
\hline & Don't know & $0.0 \%$ & $4.4 \%$ & $2.8 \%$ & $1.1 \%$ & $3.6 \%$ & $2.5 \%$ & \\
\hline & Never tried & $62.0 \%$ & $64.2 \%$ & $63.4 \%$ & $14.4 \%$ & $10.9 \%$ & $12.5 \%$ & \\
\hline & Total & 163 & 296 & 459 & 187 & 220 & 407 & \\
\hline
\end{tabular}

${ }^{1}$ The bracketed qualifier (as someone under the age of 18) was included in the interviewer administered survey but not the self-administered survey.

A six-point Likert scale was used and the original response options were later combined into three categories for chi-square tests: 'Easy' included options 'Easy' and 'Very easy'; 'Difficult' included 'Difficult' and 'Very difficult'; and 'Don't know' included 'Don't know' and 'Never tried'.

** indicates $p<0.001$ in chi-square tests comparing the 16-17 and 18-19 age groups over these three response categories.

When the sample was split by survey modality to be analysed separately, whether or not there was a significant age-difference was consistent across all items except one. For 'the last time you tried, how easy was it for you as someone under the age of 18, to buy alcohol from the bottle store?', there was no significant age difference in the online sample, while the age difference was significant in the F2F sample and when the two modalities were combined. 


\section{Drinking locations and retail outlets}

The respondents were asked about every location they drank at, during their last risky drinking session. This risky session was defined as the last time they consumed 7 or more standard drinks in one sitting. Alcohol quantity was estimated using the standard drink approach, a validated method also used in the NDSHS (4). In Australia, a 'standard drink' contains $10 \mathrm{~g}$ of alcohol and a visual guide was provided with the number of standard drinks in common beverages.

Drinking locations were classed as either non-licensed venue such as private homes, or licensed venues such as pubs and clubs. In both survey modalities, $90 \%$ of the sample consumed alcohol at some point in their last risky drinking session within a non-licensed venue such as a private home.

The respondents were also asked about the source of their alcohol - if purchased from a bottle store or within a licensed venue. Alcohol consumed within private locations was purchased from a retail outlet. The distance to respondents' usual liquor outlet was assessed using the eight multiple choice options of $<1 \mathrm{~km}, 1-2 \mathrm{~km}, 2-5 \mathrm{~km}, 5-10 \mathrm{~km}, 20-50 \mathrm{~km},>50 \mathrm{~km}$, and 'I don't have a 'usual' outlet. These distances were described in kilometres as well as in approximate time required if walking or driving. Seventy percent of the F2F sample lived less than $2 \mathrm{~km}$ from their usual bottle store $(\mathrm{N}=351)$. In the metropolitan areas, the majority (63\%) lived less than $1 \mathrm{~km}$ from their usual liquor outlet. Excluding the $9.8 \%$ who did not have a usual outlet, there were no significant age or gender differences.

\section{Licensed venues}

Respondents were asked 'the last time you went to a licensed venue (pub, club), did they require you to present your ID?' Their selection of the five multiple choice options are presented in table 2 .

Over half of the 16-17 year olds had previously attempted to enter a licensed venue (57\% males, $56 \%$ females). Of these young people, the majority (51\%) did not have their ID checked the last time they tried to enter a licensed venue. 
Males aged 16-17 who had ever attempted to enter a licensed venue, consumed significantly more at their last risky drinking session compared to their counterparts who had never tried to enter a licensed venue before (13.80 vs 16.35 standard drinks; Mann-Whitney $\mathrm{U}=4736, \mathrm{n}=218, \mathrm{z}=-2.34, \mathrm{p}=.02$ ). There were no significant differences amongst underage females.

Table 2. Identification requirements for last visit to a licensed venue

\begin{tabular}{lccc} 
& $\begin{array}{c}16-17 \\
\text { year olds }\end{array}$ & & $\begin{array}{c}18-19 \\
\text { year olds }\end{array}$ \\
\cline { 1 - 2 } They didn't check for ID & $51.2 \%$ & & $13.6 \%$ \\
Used own ID to get in & $1.9 \%$ & & $84.1 \%$ \\
Used someone else's/ & $30.0 \%$ & & $1.2 \%$ \\
a false ID to get in & $10.4 \%$ & & $.5 \%$ \\
I didn't have ID so I couldn't get in & $6.5 \%$ & & $.5 \%$ \\
\hline Other & 260 & & 403
\end{tabular}

Note: the percentages in this table are calculated excluding the 202 16-17 year olds and the 4 18-19 year old respondents that had never attempted to access a venue. Scenarios such as 'not being checked for ID upon entry, but being asked for ID at the bar' could be described in the 'other' free text response option. The administration modalities were combined above as chi-square tests did not reveal any significant differences between F2F and online responses in either the 16-17 or the 18-19 year old groups ( $p>.05)$.

Of the $283 \mathrm{~F} 2 \mathrm{~F}$ respondents that had previously visited a licensed venue, almost half (46\%) had been refused service, entry or required to leave a license venue for being too intoxicated in the past 12 months. This was more commonly reported amongst 18-19 year olds (55\%) compared to $16-17$ year olds (30\%; see table 3).

Table 3. Number of times respondents were refused service, entry, or asked to leave (were 'kicked out of') licenced venue in the past 12 months.

\begin{tabular}{lccc}
\hline & $16-17$ & $18-19$ & F2F \\
\hline None & $70.1 \%$ & $45.2 \%$ & $53.7 \%$ \\
1-2 times & $19.6 \%$ & $36.0 \%$ & $30.4 \%$ \\
3-4 times & $7.2 \%$ & $8.6 \%$ & $8.1 \%$ \\
$5-6$ times & $0.0 \%$ & $5.4 \%$ & $3.5 \%$ \\
7-8 times & $2.1 \%$ & $1.6 \%$ & $1.8 \%$ \\
$\geq 9$ times & $1.0 \%$ & $3.2 \%$ & $2.5 \%$ \\
\hline Total Valid & 97 & 186 & 283 \\
\hline Never been to a & 67 & 1 & 68 \\
licensed venue & 164 & 187 & 351 \\
\hline Total & & &
\end{tabular}




\section{Policy support}

Respondents ranked their degree of support for eight measures intended to reduce the problems associated with alcohol use (see table 4). Most of these items were based on those used within the NDSHS. Policies which were supported by the majority included (i) increasing the price of a standard drink [by 20ф] if the extra $20 \notin$ was used to support prevention and treatment of alcohol problems, (ii) requiring information on national drinking guidelines on all alcohol containers, (iii) limiting advertising for alcohol on TV until after $9.30 \mathrm{pm}$, and (iv) limiting advertising where the majority of the audience is likely to be under 18. There was a significant, but modest, positive correlation in levels of support between the two price-based policies (Spearman's rho $=.40, \mathrm{n}=351, \mathrm{p}<0.001$ ). However, there was no significant correlation in levels of support for these two policies and the quantity of alcohol consumed at the last risky drinking session.

Females were significantly more likely to report higher levels of support for all measures except raising the legal drinking age, and limiting advertising for alcohol on TV until after 9.30pm. The 16-17 year olds expressed greater support for increasing the price of alcohol by $20 \notin$ per standard drink, and for all pubs to close by 1am compared to the 18-19 year olds. In contrast, the 18-19 year olds were more likely to support raising the legal drinking age, and limiting advertising for alcohol where the majority of the audience is likely to be under 18 . 
Table 4. Support for measures to reduce the problems associated with alcohol use

\begin{tabular}{|c|c|c|c|c|c|c|c|}
\hline & $\begin{array}{l}\text { Strongly } \\
\text { support }\end{array}$ & Support & $\begin{array}{l}\text { Neither } \\
\text { support } \\
\text { nor } \\
\text { oppose } \\
\end{array}$ & Oppose & $\begin{array}{l}\text { Strongly } \\
\text { oppose }\end{array}$ & $\begin{array}{l}\text { Don't } \\
\text { know }\end{array}$ & $\mathrm{n}$ \\
\hline $\begin{array}{l}\text { Increasing the price of alcohol by } 20 \$ \text { per } \\
\text { standard drink }\end{array}$ & $1.7 \%$ & $11.1 \%$ & $12.0 \%$ & $45.0 \%$ & $29.1 \%$ & $1.1 \%$ & 351 \\
\hline $\begin{array}{l}\text { Increasing the price of a standard drink if the } \\
\text { extra } 20 \Phi \text { was used to support prevention and } \\
\text { treatment of alcohol problems }{ }^{\mathrm{b}}\end{array}$ & $13.4 \%$ & $51.9 \%$ & $14.5 \%$ & $14.8 \%$ & $4.8 \%$ & $.6 \%$ & 351 \\
\hline Raising the legal drinking age ${ }^{c}$ & $1.7 \%$ & $7.7 \%$ & $6.3 \%$ & $41.3 \%$ & $42.5 \%$ & $.6 \%$ & 351 \\
\hline All pubs to close by $1 \mathrm{am}^{\mathrm{d}}$ & $2.8 \%$ & $13.7 \%$ & $12.3 \%$ & $40.5 \%$ & $29.9 \%$ & $.9 \%$ & 351 \\
\hline $\begin{array}{l}\text { Limiting advertising for alcohol on TV until } \\
\text { after } 9.30 \mathrm{pm}\end{array}$ & $18.2 \%$ & $51.9 \%$ & $14.5 \%$ & $11.1 \%$ & $2.6 \%$ & $1.7 \%$ & 351 \\
\hline $\begin{array}{l}\text { Banning alcohol sponsorship of sporting } \\
\text { events }\end{array}$ & $9.1 \%$ & $26.3 \%$ & $26.0 \%$ & $29.4 \%$ & $8.0 \%$ & $1.1 \%$ & 350 \\
\hline $\begin{array}{l}\text { Requiring information on national drinking } \\
\text { guidelines on all alcohol containers }\end{array}$ & $8.9 \%$ & $52.6 \%$ & $22.6 \%$ & $12.3 \%$ & $1.4 \%$ & $2.3 \%$ & 350 \\
\hline $\begin{array}{l}\text { Limiting advertising for alcohol where the } \\
\text { majority of the audience is likely to be under } \\
18^{9}\end{array}$ & $21.4 \%$ & $55.4 \%$ & $14.0 \%$ & $8.0 \%$ & $.3 \%$ & $.9 \%$ & 350 \\
\hline
\end{tabular}

Note. Mann-Whitney U tests compared levels of policy support across gender (male $n=177-179$, female $n=171-172$ ), and age (16-17 year olds $n=163-164$, 18-19 year olds $n=186-187)$. While analyses were run with 5 response options, with 'don't know' (<2\% of responses) and 'neither support nor oppose' combined, the levels reported below combine the categories of 'strongly support' and 'support' for ease of reporting.

a Levels of support were higher amongst females ( $16 \%$ females \& $10 \%$ males support; $U=13542, z=-2.08, p=.04)$ and 16 17 year olds (14\% 16-17 year olds \& $12 \% 18-19$ year olds support; $U=13347, z=-2.23, p=.03$ ).

b Females more likely to support ( $67 \%$ females \& $61 \%$ males; $U=13200, z=-2.50, p=.01)$.

c $18-19$ year olds more likely to support (16-17=4\%, 18-19=14\% support; $U=12856, z=-2.83, p=.005)$.

d Levels of support were higher amongst females (20\% females \& $13 \%$ males; $U=13142, z=-2.49, p=.01)$ and younger respondents $(16-17=17 \%, 18-19=16 \%$ support; $U=13338, z=-2.22, p=.03)$.

e Females more likely to support ( $47 \%$ females \& 24\% males; $U=10774, z=-4.95, p=.001)$.

${ }^{f}$ Females more likely to support ( $67 \%$ females \& 55\% males; $\left.U=13220, z=-2.41, p=.02\right)$.

$\mathrm{g}$ Levels of support were higher amongst female (83\% females \& $71 \%$ males; $U=12907, z=-2.81, p=.005)$ and older respondents $(16-17=68 \%, 18-19=84 \%$ support; $U=12031, z=-3.78, p=.001)$. 


\section{Disc ussion}

The study showed that the method was viable for reaching sentinel samples of young drinkers consuming alcohol at risky levels and assessing policy-related data. This study found that age- or intoxication-based restrictions to alcohol were commonly circumvented by risky drinking Australian teenagers. Most participants reported they did not have their age verified the last time they tried to enter a licensed venue, including the vast majority $(75 \%)$ of under aged participants who had tried. Of course, caution is required in generalising this to the broad population - there may be features of risky drinkers (physical appearance - looking older; access to venues that do not comply with the regulations) that are not evident in the broader population of young people. Forty-six percent of those who had been to a licensed venue before, had been refused service, entry or required to leave a venue for being too intoxicated in the past 12 months.

Other studies purport that a significant proportion of alcohol consumed in heavy episodes is sourced from retail outlets $(25,26)$. The last time they tried, almost half $(49 \%)$ of participants aged under 18 rated it as 'easy' or 'very easy' for them to purchase alcohol from the bottle shop. This is consistent with the 30\% of Australian 16-17 year old drinkers reporting having purchased alcohol from a retail outlet (27). Also, $90 \%$ of this study's sample also consumed retail purchased alcohol at a private location at some point in their last risky drinking session. This supports the argument imperative that discussion around risky consumption should include packaged liquor.

There was majority support for limiting alcohol advertising where the majority of the audience is likely to be under 18, and through television watershed times. Despite these two policies making explicit or implicit reference to an under 18 age group, they were similarly supported amongst those over and under 18. There is evidence that limiting adolescents' exposure to alcohol advertising would impact on their subsequent intention to drink and consumption patterns (e.g.28).

While there is evidence that price mechanisms can influence consumption and harm, the strategy is contentious. For example, in a previous large scale measure of Australians' views, 29\% supported 
'increasing the price of alcohol' and $43 \%$ supported 'increasing the tax on alcohol products to pay for health, education, and the cost of treating alcohol related problems'. There was little support among those who drank more - respectively $7 \%$ and $16 \%$ amongst those aged $14+$ who were drinking more than 4 standard drinks at least weekly (4). In comparison, this study reported higher levels of price policy support even amongst this risky drinking cohort of young people. The two similar proposed measures, with the same price increase for the same unit of alcohol, received substantially different levels of support. There was majority support (65\%) if the measure description included how the $20 \%$ revenue per standard drink would be used for prevention and treatment, and very low support (13\%) if there was no description of how the money would be specifically allocated This suggests that measures of support for policy initiatives need to present specific scenarios to accurately reflect attitudes.

However, being more specific did not result in greater support for another measure described by others as 'restricting late night trading of alcohol' (4). Though there is evidence of a positive relationship between later trading hours, greater levels of intoxication and harm (29, 30); less than a fifth (18.1\%) of our sample supported the measure for 'all pubs to close by $1 \mathrm{am}$ '.

Of the four age-related differences in support for policies, the greatest effect sizes were observed when the 18-19 year olds were more supportive than the 16-17 year olds - namely, to raise the legal drinking age, and to limit advertising for alcohol where the majority of the audience is likely to be under 18 . These may be due to cohort effects, or suggest that these policies are particularly age sensitive.

\section{Methodological considerations}

While deliberate misreporting is an issue for all self-administered surveys, self-report measures are considered a generally valid measure for adolescent drug use (31-33). Reports of venue access etc. are consistent with other studies.

This study used a non-probability-based sampling framework and cannot be conclusively stated as representative of all 16-19 year old risky drinkers. However, as discussed in the methods section, this 
sample reported similar rates of high risk drinking $(11+$ standard drinks twice monthly) to age-matched risky drinking samples recruited using representative sampling techniques.

As this sample was by definition, heavier drinkers, their behaviour is likely more determined in the access attempts for alcohol. That is to say, as the sample is not representative of others' in their age bracket, nor are their attempts at gaining access to alcohol. Legislation governing access to alcohol varies even within Australian states, so the results of this study may not generalise outside of Australia.

\section{Implications}

The process of moderating alcohol access through point of sale age based restrictions did not affect those over the age of 18 , which is perhaps not surprising, but they were also commonly bypassed by risky drinkers in this sample who were under the legal purchase age. This common circumvention suggests that there is scope for greater regulation in identification verification processes. Further, as there was a high prevalence of drinking in private locations, public health policies around alcohol need to not only focus on entertainment district activity, but also alcohol consumed within private residences.

Price-based policies that are linked to the volume of alcohol apply to licenced and private venues alike, are relevant to people of all ages, have a strong evidence base, and in this study were supported even by a majority of young high risk drinkers when the hypothesised price increase was modest and when it was specifically aimed to support prevention and other responses to alcohol related problems. 


\section{References}

1. Livingston M. Trends in non-drinking among Australian adolescents. Addiction. 2014 Apr 10. PubMed PMID: 24717214.

2. White V, Bariola E. Australian secondary school students' use of tobacco, alcohol, and overthecounter and illicit substances in 2011. Victorian Department of Health \& The Cancer Council Victoria, 2012.

3. Livingston M. Recent trends in risky alcohol consumption and related harm among young people in Victoria, Australia. Australian and New Zealand Journal of Public Health. 2008;32(3):266-71.

4. Australian Institute of Health and Welfare. 2010 National Drug Strategy Household Survey report. 2011.

5. Manning M, Smith C, Mazerolle P. The societal costs of alcohol misuse in Australia. Trends and Issues in Crime and Criminal Justice. 2013;454:1-6.

6. Chikritzhs T, Stockwell T, Heale P, Dietze P, Webb M. Trends in Alcohol-Related Road Injury in Australia, 1990-1997. Perth: National Drug Research Institute, 2000.

7. Matthews S, Chikritzhs T, Catalano P, Stockwell T, Donath S. Trends in alcohol-related violence in Australia, 1991/92-1999/00. Perth: National Drug Research Institute,

Curtin University of Technology, 2002.

8. Fogarty A, Chapman S. What should be done about policy on alcohol pricing and promotions?

Australian experts' views of policy priorities: a qualitative interview study. BMC public health. 2013;13(1):610-.

9. Prepared for the National Preventative Health Taskforce by the Alcohol Working Group. Preventing alcohol-related harm in Australia: a window of opportunity. Commonwealth of Australia, 2009.

10. Babor TF, Caetano R, Casswell S, Edwards G, Giesbrecht N, Graham K, et al. Alcohol: No Ordinary Commodity. Research and Public Policy. 2nd ed. Oxford: Oxford University Press; 2010.

11. Doran CM, Byrnes JM, Cobiac LJ, Vandenberg B, Vos T. Estimated impacts of alternative Australian alcohol taxation structures on consumption, public health and government revenues. Med J Aust. 2013 Nov 4;199(9):619-22. PubMed PMID: 24182229.

12. Trifonoff A, Andrew R, Steenson T, Nicholas R, Roche AM. Liquor Licensing in Australia: An Overview. Adelaide, South Australia: National Centre for Education and Training on Addiction (NCETA), Flinders University, 2011.

13. Burgess M, Moffatt $\mathrm{S}$. The association between alcohol outlet density and assaults on and around licensed premises. Sydney: NSW Bureau of Crime Statistics and Research, 2011.

14. Rowland B, Toumbourou JW, Satyen L, Tooley G, Hall J, Livingston M, et al. Associations between alcohol outlet densities and adolescent alcohol consumption: A study in Australian students. Addictive Behaviors. 2014;39(1):282-8.

15. Fogarty AS, Chapman S. "Like throwing a bowling ball at a battle ship" audience responses to Australian news stories about alcohol pricing and promotion policies: a qualitative focus group study. PloS one. 2013;8(6):e65261. PubMed PMID: 23755205. Pubmed Central PMCID: 3673948.

16. Stockwell T, Jinhui Z, Martin G, Macdonald S, Vallance K, Treno A, et al. Minimum Alcohol Prices and Outlet Densities in British Columbia, Canada: Estimated Impacts on Alcohol-Attributable Hospital Admissions. American Journal of Public Health. 2013;103(11):2014-20. PubMed PMID: 90627271.

17. Stockwell T, Thomas G. Is alcohol too cheap in the UK? The case for setting a Minimum Unit Price for alcohol. Institute of Alcohol Studies, Centre for Addictions Research, University of Victoria, 2013.

18. Lonsdale AJ, Hardcastle SJ, Hagger MS. A minimum price per unit of alcohol: A focus group study to investigate public opinion concerning UK government proposals to introduce new price controls to curb alcohol consumption. BMC Public Health. 2012;12(1023).

19. Wilkinson C, Room R, Livingston M. Mapping Australian public opinion on alcohol policies in the new millennium. Drug and Alcohol Review. 2009;28(3):263-74.

20. Stockwell T, Chikritzhs T, Hendrie D, Fordham R, Ying F, Phillips M, et al. The public health and safety benefits of the Northern Territory's Living with Alcohol programme. Drug and Alcohol Review. 2001;20(2):167-80. 
21. Chikritzhs T, Stockwell T, Pascal R. The impact of the Northern Territory's Living With Alcohol program, 1992-2002: revisiting the evaluation. Addiction. 2005 Nov;100(11):1625-36. PubMed PMID: 16277624.

22. Stafford J, Burns L. Australian Drug Trends 2012. Findings from the Illicit Drug Reporting System (IDRS). Sydney: National Drug and Alcohol Research Centre, University of New South Wales, 2013.

23. Sindicich N, Burns L. Australian Trends in Ecstasy and related Drug Markets 2012. Findings from the Ecstasy and Related Drugs Reporting System (EDRS). Sydney: National Drug and Alcohol Research Centre,

University of New South Wales., 2013.

24. Victorian Drug and Alcohol Prevention Council. 2009 Victorian Youth Alcohol and Drug Survey. 2010.

25. McKetin R, Livingston M, Chalmers J, Bright D. The role of off-licence outlets in binge drinking: a survey of drinking practices last Saturday night among young adults in Australia. Drug and Alcohol Review. 2014;33(1):51-8.

26. Dietze PM, Livingston M, Callinan S, Room R. The big night out: What happens on the most recent heavy drinking occasion among young Victorian risky drinkers? Drug Alcohol Rev. 2014 Mar 14. PubMed PMID: 24628682.

27. Australian Institute of Health and Welfare. 2007 National Drug Strategy Household Survey: detailed findings. Canberra: AIWA, 200818 December 2008. Report No.

28. Jones SC, Magee CA. Exposure to Alcohol Advertising and Alcohol Consumption among Australian Adolescents. Alcohol and Alcoholism. 2011 September 1, 2011;46(5):630-7.

29. Chikritzhs T, Stockwell T. The Impact of Later Trading Hours for Australian Public Houses (Hotels) on Levels of Violence. Journal of Studies on Alcohol. 2002;5(63):591-9.

30. Miller P, Pennay A, Droste N, Jenkinson R, Quinn B, Chikritzhs T, et al. Patron Offending and Intoxication in Night-Time Entertainment Districts (POINTED) final report. Canberra: National Drug Law Enforcement Research Fund (NDLERF), 2013.

31. Lintonen T, Ahlström S, Metso L. The reliability of self-reported drinking in adolescence. Alcohol and Alcoholism. 2004 July 1, 2004;39(4):362-8.

32. Oetting ER, Beauvais F. Adolescent Drug Use: Findings of National and Local Surveys. Journal of Consulting \& Clinical Psychology. 1990;58(4):385-94.

33. Winters KC, Stinchfield RD, Henly GA, Schwartz RH. Validity of Adolescent Self-Report of Alcohol and Other Drug Involvement. Substance Use \& Misuse. 1990;25(9 supp 11):1379 - 95.

\section{Funding Sources}

This study was supported by Australian National Preventive Health Agency (140ALL2011). The National Drug Research Institute of the Health Sciences Faculty at Curtin University, and the National Drug and Alcohol Research Centre of the University of New South Wales ares supported by funding from the Australian Government under the Substance Misuse Prevention and Service Improvement Grants Fund.

\section{Acknowledgments}

The authors thank staff members from the National Drug Research Institute (Curtin University), National Drug and Alcohol Research Centre (University of New South Wales), Turning Point Alcohol and Drug Centre (Monash University), South West Community Drug Service Team (St John of God Bunbury Hospital), the office for the Commissioner for Children and Young People, the Department of Health (WA, NSW, VIC), Mission Australia's Drug and Alcohol Youth Service, and other staff who contributed to the project. The authors are also grateful to the young people who participated in the study. 